\title{
Sport for Social Change With Aotearoa New Zealand Youth: Navigating the Theory-Practice Nexus Through Indigenous Principles
}

\author{
Jeremy Hapeta, Rochelle Stewart-Withers, and Farah Palmer \\ Massey University
}

\begin{abstract}
Indigenous worldviews and scholarship are underrepresented and underdeveloped in sport for development and wider sport management spaces. Given many sport for social change initiatives target Indigenous populations, this is concerning. By adopting a Kaupapa Māori approach, a strengths-based stance, and working together with two plus-sport and sport-plus cases from provincial and national New Zealand rugby settings: the Taranaki Rugby Football Union's and Feats' Pae Tawhiti (seek distant horizons) Māori and Pasifika Rugby Academy and the E Tū Toa (stand strong), hei tū he rangatira (become a leader) Māori Rugby Development camps, the authors provide an illustration of Indigenous theory-practice. They argue sport for social change practices that focus on Indigenous peoples would be greatly improved if underpinned by the principles of perspective, privilege, politics, protection, and people. Thus, any sport for social change praxis seeking to partner with Indigenous communities ought to be informed by Indigenous philosophical viewpoints.
\end{abstract}

Keywords: athlete development, development through sport, social development, sport for development, youth sport

This article seeks to make higher level contributions to the nexus between theory and practice within sport for social change by shining light on Indigenous theory and practice in Aotearoa New Zealand (NZ). First, we acknowledge the forward and timely thinking of this special issue for providing the opportunity and space to consider the role of theory in informing practice, posing the questions: Is/can there be a universal theory of sport for social change? And, can Indigenous practice inform sport for social change theory? Since Indigenous perspectives are currently missing or marginalized in sport-for-development (SFD) research, this study demonstrates how such perspectives can provide important insights for the SFD field. We argue that, from our perspective as Māori (Indigenous people to NZ) scholars, there cannot be a universal theory; however, there is some universality of principles that ought to underpin SFD research and practice by, with, and for Indigenous peoples.

Research and practice are influenced by philosophical paradigms, which make explicit a position about the nature of reality (ontology), how we can know about it (epistemology), and what role values play in research (axiology). As Māori researchers, with an interest in Indigenous scholarship more broadly, we apply a Kaupapa Māori (KM) approach (generally, but not exclusively research by, with, and for Māori) (Hapeta, Palmer, Kuroda, \& Hermansson, 2019). We argue that Indigenous worldviews therefore are theory, ${ }^{1}$ as Indigenous philosophical paradigms typically presume a relational ontology, which is about a place-based

Hapeta is with the School of Sport, Exercise and Nutrition, College of Health, Massey University, Palmerston North, New Zealand. Stewart-Withers is with the School of People, Environment and Planning, College of Humanities and Social Sciences, Massey University, Palmerston North, New Zealand. Palmer is with the School of Management, Massey Business School, Massey University, Palmerston North, New Zealand. Hapeta (j.w.hapeta@massey.ac.nz) is corresponding author. existence and practices that link to particular territories (DavidsonHunt \& O'Flaherty, 2007; Smith, 2013).

For most Indigenous peoples, there is no theory-practice divide because theoretical understandings of the world are inseparable from the past, present, and future practices of life (Arbon, 2008; Lee, 2009). Everyday practices are informed by theories about creation, cosmology, ancestors, genealogy accounts, values and principles, governance and leadership structures, rules, and norms which determine behaviors and connections in the material and nonmaterial worlds, which are context and event specific (Henry \& Foley, 2018; Smith, 2013). We argue that practice is therefore an embodied expression of theory. ${ }^{2}$ It is about a "profoundly relational way of thinking predicated upon profoundly relational ontologies" (Reddekop, 2014, p. 6). The practice of sport represents one of the most embodied expressions of theory that is relational and reflective of philosophical paradigms that are contested in communities and societies where they exist.

In deliberating the theory-practice gap as it relates to academic scholarship, what counts as theory and whose theories are privileged needs consideration. "Knowledge is power, but power is also knowledge" (Alvares, 1992, p. 230) because power determines what is knowledge and what is not (also see Gardner \& Lewis, 2000; Smith, 2013). This issue has been recently argued in the SFD space (Spaaij, Schulenkorf, Jeanes, \& Oxford, 2018 ${ }^{3}$ ). The issue of power and knowledge through research likewise becomes one of how, where, and for whom Indigenous theories and practices are documented or evidenced. ${ }^{4}$ The theory-practice gap is also one of translation, enabling outsiders to learn and grow their insights while simultaneously maintaining the ethos of alternative worldviews such as Indigenous worldviews (Henry \& Foley, 2018).

Of value to our study are the foundational works by Indigenous scholars discussing core principles that are important when working with Indigenous peoples. This work has tended to focus on 
research, not on the sport or the development space. Rigney (1999), for example, wrote of resistance, political integrity, and privileging Indigenous voices. Smith's (2006) seminal work highlighted values such as "titiro" (look), "whakarongo" (listen), and "korero" (speak) that is developing an understanding first in order to find a place from which to speak (maybe). Meanwhile, Kennedy and Wehipeihana (2006) argued the importance of capacity building and clear benefits to those being researched. Thus, the principles that we see to be important to consider in this article are:

- Perspective-this is about being informed by Indigenous culture and values systems (philosophical positionality). It also acknowledges the importance of one's place of standing as this influences their perspective;

- Privilege - this takes for granted Indigenous ways of knowing, being and doing as legitimate, and refers to the privileging of Indigenous voices.

- Politics - this is about being underpinned by political integrity that values Indigenous struggles, resistance, and the need for autonomy and self-determination.

- Protection-this is about guardianship, remaining culturally safe, reclaiming the right to have a voice and share knowledge, values and processes underpinned by Indigenous ways of creating and embodying knowledge. This also includes "ethics of care" for places and people involved in this process;

- People-this acknowledges that past, present, and future relationships play a vital role and that people also need to be empowered for "social change" and transformation to occur.

In addressing the theory-practice nexus via these principles, it is important to acknowledge the "place" where this nexus is being researched (Aotearoa NZ) and the Indigenous people of this land (Māori). Māori is the modern-day term used to refer to the tangata whenua (people of the land) in Aotearoa, now referred to as NZ. The 2013 Census in NZ revealed that $15.7 \%$ of NZs population were of Māori descent, but fewer (13.4\%) self-identified as Māori of which more than half identified with two or more ethnic groups (Statistics New Zealand, 2013), suggesting cultural identity for Māori is complex. In 2015, it was estimated that more than 712,000 New Zealanders identified as Māori, and $51 \%$ of the Māori population were 24 years of age and younger (Statistics New Zealand, 2015).

For a thousand years, a Māori worldview influenced everyday life in Aotearoa. For instance, Māori means "normal" and only became meaningful to tangata whenua (Indigenous people) as a collective identity due to colonization by Anglo-Saxon missionaries and settlers (referred to now as Pākehā) and their institutions. In adopting a KM research approach, this article provides an illustration of Indigenous theory informing practice in the sport for social change space, which contributes to the sport for social change corpus of knowledge. In addition to the fact that Indigenous worldviews (theory) and ways of being and doing (practice) are often silenced (Harvey, 2002) and/or positioned at the margins in many disciplines (Smith, 2006; Smith, Maxwell, Puke, \& Temara, 2016), two other concerns underpin this article. The following are the sport for social change agendas:

- By nature are inherently deficit (Coalter, 2010, 2013, 2015; Cunningham, 2015) and marginalized people often bear the brunt of this deficit lens.

- Often overlook community members as knowledge sources when looking to the "world of evidence" in decision making (Coalter, 2007).
With this in mind, we reinforce the importance of assuming a strengths-based stance (Paraschak, 2013) as Indigenous and KM scholars, and we illustrate this argument using the sport for social change case studies based in Aotearoa NZ. The research originates from a "ground-up" perspective (Pihama, Cram, \& Walker, 2002) and later considers a "top-down" viewpoint, examining how sport (in these cases rugby) is used to positively transform the lives of Māori and Pasifika ${ }^{5}$ youth in NZ while simultaneously recognizing a higher ontological relational positionality.

This article is structured as follows: Initially, we overview the sport for social change literature globally to locate the need of this article. Following this, the next section introduces the two cases from provincial and national NZ rugby (NZR) settings: the Taranaki Rugby Football Union (TRFU) and Feats' (Pae Tawhiti) Māori and Pasifika Rugby Academy (MPRA) and the E Tū Toa (stand strong), hei tū he rangatira (become a leader) Māori Rugby Development (ETTMRD) camps. This section also clarifies the conceptual tools and methods used to analyze the data. The following sections present the results of the case studies independently and then integrate them in the discussion. Finally, the article concludes by offering recommendations and implications for future sport for social change research, especially with Māori, Pasifika, and other Indigenous populations globally.

\section{Sport for Social Change Debates: Locating an Indigenous Ontology}

In reflecting on 15 years of dedicated SFD research, Schulenkorf (2017) stated that the field "has experienced significant growth and progressive sophistication over time" (p. 249). Major contributions to this scholarship have come from the disciplines of sport management, international development, and sociology (e.g., Collison, Darnell, Giulianotti, \& Howe, 2018; Levermore \& Beacom, 2009; Schulenkorf \& Adair, 2014; Schulenkorf, Sherry \& Rowe, 2016; Young \& Okada, 2014). This literature has raised a number of critical challenges for practice. For example, it has been found that much of what occurs in the SFD field is messy, many claims made lack evidence (Coalter, 2013; Jeanes \& Lindsey, 2014; Levermore, 2011; Rossi \& Jeanes, 2016), and what is argued can often be contested (Coalter, 2015; Levermore, 2011). Although sport has the capacity to create transformation, other scholars have also warned that "there is a need to think more clearly, analytically and less emotionally about 'sport' and its potential ... which hides much more than it reveals" (Coalter, 2007, p. 7; Rossi \& Jeanes, 2018). Some contributions have sought to address in particular the theory-practice gap in SFD (e.g., Lyras \& Welty Peachey, 2011; Schulenkorf, 2012). In this context, Coalter (2007) has suggested that bridging theory and practice might be difficult for those who are "heavily invested" in sport:

with demanding, if often ill-informed, masters . . nobody in high office reads social science journals . . . as one ascends the intervention hierarchy the capacity to absorb complex information dwindles by the bullet point . . . some of the key target audiences will not read this, I hope that those who might talk to them . . [and] eventually engage in the necessary conversation. (p. 7)

As Māori academics, we play our part by contributing an Indigenous perspective to the conversation on the nexus between theory and practice in SFD. In NZ, organized sport is an institution that appeals to Māori and is an area where Māori's achievement and excellence is visible and celebrated. As a result, Māori are 
significant contributors to sport in NZ, and Māori adults and young people participate in it in high numbers. For instance, the 2013/ 2014 Active NZ survey found that $81.2 \%$ of Māori participated in sport and recreation activities in a 4-week period, $68.2 \%$ of Māori participated in a 7-day period, and Māori averaged 4.2 sport activities in a 12-month period. Enjoyment was the primary reason for Māori participation, followed closely by health and fitness (Vercoe, 2017).

This article focuses on Māori youth development in and around rugby. Aligned with counterdeficit views, this study adopts a strengths-based stance, positioned within a KM perspective (Pihama et al., 2002) that places Māori and Pasifika youth at the center of the research. Moreover, alongside the plus-sport case study with socalled "at-risk" youth (who were in fact failed by the system, not the contrary), a case study of rangatahi Māori who were flourishing in their rugby (sport-plus) and experiencing a relative degree of success and confidence in education insofar as they were still engaged in school (Ware \& Walsh-Tapiata, 2010) is also presented.

\section{Methods}

This KM-informed article presents two specific case studies (Stake, 1995), both of which are distinct initiatives from the NZR context. The first is a local example, the MPRA, whereas the other is a national example, ETTMRD. The first has a "plus-sport" focus (MPRA), and the other can be characterized as "sport-plus," with the intent to promote positive social change for rangatahi Māori and/or Pasifika youth specifically. Although they are rugby-specific cases, which cannot be generalized, they may have relevance and provide potential implications for the global sport for social change community of academics and practitioners to consider.

\section{The Plus-Sport and Sport-Plus Cases}

In the context of this article, we applied SFD definitions to rugby to positively influence Māori and Pasifika youth, encouraging them to reconnect with their place of belonging (türangawaewae) and stand strong (e tū toa). Within the body of SFD literature, the following three approaches are usually taken: "sport-only," "plus-sport," and "sportplus." Sport-only provides activities and sporting opportunities with no other associated outcomes. Plus-sport's primary focus is on developing the individuals or communities first, with sport used to attract people (Spaaij, 2013). Finally, with sport-plus, sporting pursuits often get augmented with other development opportunities, a secondary focus outside of the specific sport outcomes (Cunningham, 2015).

Conceptually, assuming a "ground-up" position from a KM perspective means acknowledging tūrangawaewae (place of standing; place of belonging), which is terrestrially founded upon the whenua (land base, foundation) and celestially in whakapapa (genealogy) (Durie, 1999). That is, these local plus-sport (MPRA) and national sport-plus (ETTMD) rugby case studies examined the lived realities (ontologically) of youth within these rugby settings and their respective facilitators/coaches involved with delivering these sport for social change initiatives. These rugby-specific cases explored how the lives of these youth were enhanced and/or transformed, interrogating the impact of their involvement in these rugby initiatives based on predominantly Indigenous principles.

\section{Research Participants}

To protect the identities of rangatahi (10 in total), participants were given pseudonyms: Tahi (1), Rua (2), Toru (3), and so on, the Māori words for numbers 1-10. The MPRA/Feats' facilitators consented to us using their actual positions and identities (see Table 1). The "plus-sport" MPRA participants (four youth and four facilitators) and "sport-plus" (six youth) ETTMRD sites met case study conventions (Stake, 1995), but we also acknowledge their limitations in that they are contextualized spaces. In terms of ethical approval, this project was evaluated by peer review and deemed low risk, and notification was lodged with Massey University's Human Ethics Office.

Case study 1: The local MPRA. The MPRA case study is a partnership initiative between the TRFU and a local education provider "Feats" (also called Pae Tawhiti which means to "seek out distant horizons") that promotes education "plus-sport." Rugby is a conduit in attempt to change the lives of these youth who were apparently "at risk" insofar as they had either dropped out of mainstream education or had no formal qualifications to enable them to flourish in future. These learners were enrolled into Feats' National Certificate of Educational Achievement (NCEA) Levels 1 and 2 programs and were deliberately targeted by the Feats and TRFU "plus-sport" partnership. Data collection at the site included semistructured, focus-group interviews with past graduates from 2017 (pseudonyms Tahi, Rua, Toru, and Wha) and another focus group with four of the course facilitators including Feats and TRFU staff. Interview questions were open-ended, and both focus groups occurred at their central-Taranaki (Stratford) campus. Other documents were collected and observations noted while on-site to complement the primary data gathered from the MPRA youth and other sources.

Case study 2: The National ETTMRD camps. This case study comes from a NZR centrally funded, national model specifically to cater to Māori Rugby development aspirations at the rangatahi (youth) level. Typically, the five NZ Super Rugby franchises (i.e., Blues, Chiefs, Hurricanes, Crusaders, and Highlanders) select elite-level players (which may include Māori youth) for their respective regional Under 18 (U18s) teams. These franchise teams comprise the country's top 150 U18s players. Those who miss selection realistically have no other pathway into the National Schools' U18s team. The other key feature of this site is that the majority of 150 players identified through this pathway are still engaged in mainstream education.

Typically, a NZ School's team and a "B" team, the NZ "Barbarians" (U18s), are selected from the five franchise teams. However, since 2016 in an augmented "sport-plus" initiative, mandated through the NZMRB and funded by NZR, players

\section{Table 1 Research Participants}

\begin{tabular}{lll}
\hline Research site (case study) & Research participants & Method(s) \\
\hline Feats'/TRFUs MPRA & Four youth and four facilitators & Semistructured focus groups \\
E Tū Toa Maori Rugby Development camps & Six youth (numerous coaches) & Focus group (observations) \\
\hline
\end{tabular}

Abbreviations: MPRA, Maori and Pasifika Rugby Academy; TRFU, Taranaki Rugby Football Union. 
with Māori whakapapa (genealogy) who miss selection in the franchise teams are offered an opportunity to attend Māori rugby development camps. These "sport-plus" ETTMRD camps are offered to a wider pool of players throughout the three traditional Māori regions: Te Waipounamu (South Island); Te Tini à Maui (Central and Lower North Island); and Te Hiku o te Ika (Northern, North Island). These Māori players, surplus to franchise requirements, are invited to trial for the national Māori U18s team. The main development kaupapa (purpose) for these players, however, is not necessarily about rugby. At these ETTMRD regional/national camps, coaches and facilitators use rugby to drive off-field development messages to rangatahi via Indigenous values, practices, and principles. The "E tū toa, hei tū rangatira" aspiration is that these youth will stand strong and develop into rangatira (leaders) for tomorrow. Instead of focusing only on micro and macro rugbyrelated skills, rangatahi are taught life skills and are encouraged to embrace and celebrate their whakapapa (genealogy) and identity as Māori.

Data at this site were collected throughout the first author's ethnographic observations over a week immersed in camp at the NZ Māori U18s trials. In-depth field notes and impromptu kōrero (conversations) with staff (coaches, managers, cultural advisors) and players provided rich insights. Subsequently, a follow-up focus group was conducted with a selection of the 40 rangatahi (pseudonyms Rima, Ono, Whitu, Waru, Iwa, and Tekau) once they had the opportunity to reflect upon their experiences within those settings. Two from this focus group were not part of the 2018 NZ Māori U18s trials because they made a franchise team. However, they were part of the regional Māori development camp earlier in the year and/or were involved in the 2017 National Māori camp. Thus, they were still able to provide insights and share contrasts across "mainstream" (franchise) and Indigenous "sport-plus" settings.

\section{Data Analysis: Navigating the Narratives}

In addition, this study employed multiple other data sources including: media, observations, documents, experts in the field and other secondary data "MODES" (Onwuegbuzie \& Frels, 2016). Experts included coaches and cultural advisors from the TRFU and NZ Māori All Blacks' (MAB) teams, through to the rangatahi focus group discussions which were audio-recorded and transcribed by the first author. This process aided with familiarization, the initial stage of thematic analysis (Braun \& Clarke, 2006). Initially, codes were generated to develop thematic "maps" to link across themes, which were reviewed to determine if they should be included or excluded depending on the substantive evidence (Braun \& Clarke, 2006) in order to define and name themes. This method has been used in sport research (Braun, Clarke, \& Weate, 2016) and by Indigenous wellbeing scholars (McGuire-Adams, 2017).

Due to the Indigenous principles guiding this article, a wayfinding model was used to identify and align themes. Wayfinding leadership relates to the ancient Polynesian practice of navigating the oceans using deep knowledge and intense observation of the celestial bodies in the sky and the swells of the water (Spiller, Barclay-Kerr, \& Panoho, 2015). Walker (1990) described how the Polynesian ancestors of the tangata whenua of Aotearoa (Māori in NZ) had been living in Samoa and Tonga for over a thousand years before reaching the shores of Aotearoa in AD 800 after a long voyage, which would have employed wayfinding practices. The authors (all Māori) therefore felt that the theoretical principles embodied within the five waypoints were appropriate, strengthsbased (Paraschak, 2013) approaches to thematically analyzing the data collected (McGuire-Adams, 2017) from these case studies that included Māori and Pasifika youth as contemporary wayfinders (Spiller et al., 2015).

All data were coded to search for and identify themes consistent or aligned with the following waypoints of the wayfinding model of leadership (Spiller et al., 2015) which are as follows:

1. Orientation: relates to the whole waka (sea-faring vessel) as a needle and introduces key principles of orientation (knowing where you are and where you are going).

2. Implementing values: relate to the hulls of the waka and presents guiding values to orient by. From a Te Ao Māori (Māori worldview) perspective, this can refer to tikanga (protocols) and KM principles.

3. Human dynamics: relates to the waka rudder, mast, sails and mauri (life force) stones (anchor) and relates to cultural identity, self-knowledge, alignment, collectivism, and well-being.

4. Deepening practices: relate to the cross beams on the waka and are about the planks of connectivity that connect values with practices to support a holistic view that secures interpersonal relationships.

5. Exploring and discovering destinations: speak to the island where the end is a new beginning; this element explores new worlds of possibilities for leaders (rangatira).

This tool was employed analytically so that the past, present, and future pathways for rangatahi could be mapped and navigated in regard to the sport for social change focus of this special issue. These five waypoints are reference points for the purpose of navigation and have long been used for journeying. They metaphorically relate to parts of a double-hulled ocean-going waka or sailing vessel (see Figure 1).

Thus, the waka and waypoints within the wayfinding model of leadership helped us to code, categorize, organize, and synthesize our case studies' data sets thematically from an Indigenous perspective. Thematic analysis (Braun \& Clarke, 2006) employed both semantic and latent considerations including inductive bottom-up and theoretical top-down approaches to align with the closing of the gap between lived realities and theories of sport (rugby) for

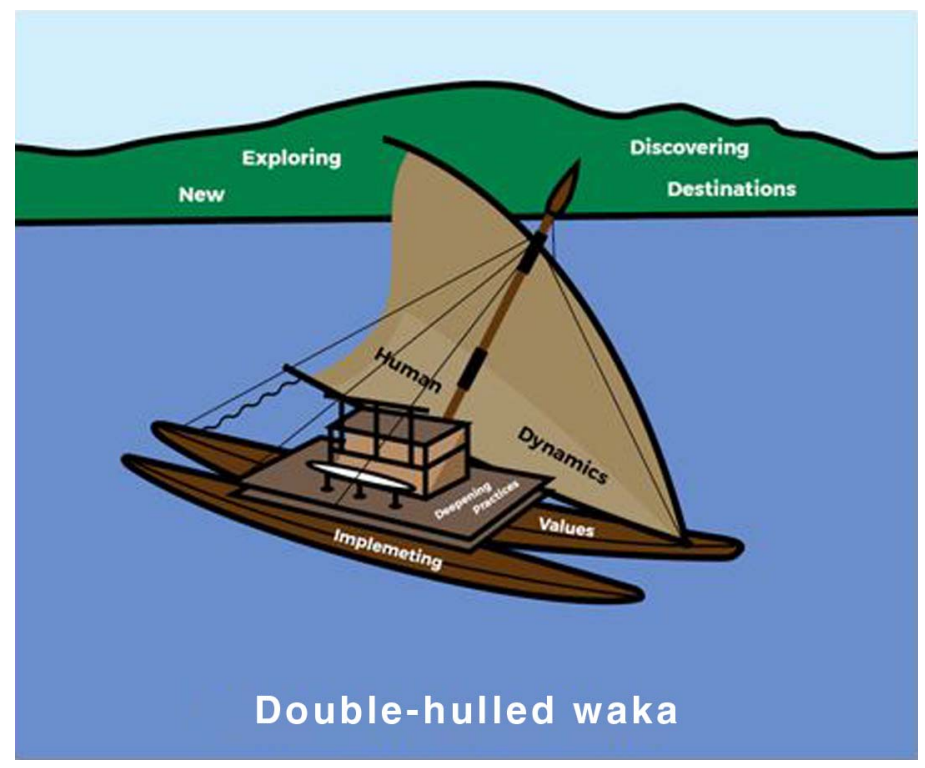

Figure 1 - A double-hulled waka. 
social change. The final phase is reporting the results; therefore, the directions that these rangatahi 'wayfinders' are heading in is discussed in the next section.

\section{Results}

\section{Feats' MPRA-An Education “Plus-Sport” Approach}

Inā kei te mohio koe ko wai koe, i anga mai koe i hea,

kei te mohio koe. kei te anga atu ki hea

If you know who you are and where you are from,

then you will know, where you are going

This whakataukī (proverb) essentially asks questions of one's cultural identity and their place of belonging (tūrangawaewae). It also relates to the purpose of this article, exploring how rangatahi are "finding their feet" and "standing tall" through the practice of Indigenous principles and values in rugby. Ultimately related to orientation (Waypoint 1), this proverb refers to knowing who you are (cultural identity), where you have been (past) in order to determine where you are (present) and where you are going (future). Due to the distinctive nature of these two sites, results are presented separately in relation to these five waypoints and are discussed together as follows.

Waypoint 1: Orientation. As a start point, at the TRFU/Feats' MPRA "plus-sport" site, rangatahi were encouraged to share their personal pepehā (narratives) which served to anchor them both terrestrially with their tūrangawaewae (place of belonging) and celestially with their tupuna (ancestors) (Durie, 1999). After the researchers shared their pepehā, MPRA youth were encouraged to consider- "who I am, who do I descend from; where do I come from and where do I belong" prompts that are an implicit part of the pepehā process (to be discussed in Waypoint 3). Pepehā were delivered in both Te Reo Māori and English by the non-Māori (Fijian and Kiribatian) youth, with varying degrees of confidence and competence witnessed from all the youth.

Waypoint 2: Implementing values. In discussing some of the key values (Waypoint 2) and lessons that the youth had instilled into them either growing up (past) or within the MPRA (present), the consensus was that a genuine respect for people and forgiveness were core values that had been taught. In relation to respect, one of the rangatahi Māori mentioned his "Nan" taught him about respecting all people, “even though I didn't learn it [in the past], but eventually I did" [now]. Although, learning forgiveness was more specific to the MPRA site than in their lives in general.

One of the key contributors to implementing this value was the academy's manager from TRFU. This reinforced the "plussport" concept because life lessons were deliberately taught, not "caught":

How you treat people. Love your enemies, as you love yourself. No matter what they do to you. Because when I was at [Mainstream] school, whenever you're feeling down, there's no one there... at school I'm sitting beside a palagi [European] so he was like scared to talk to me and I just go to him 'are you ok? (Rua).

Look after your family no matter what . . you can have an argument ... just forgive them. They can make you so angry that you want to beat them up. Just forgive them . . my Dad moved away from us when I was 6 years old . . that is what made me an angry person ... my little brother is a young angry man. I just want to teach him that there is more to life than being angry. . . I want to get that out of him. (Toru)

I reckon he taught us lots because he always used to tell us stories. That's pretty much what helped us out. Life stories, like back home in Samoa. (Wha)

In the focus group with the MPRAs facilitators, the value of respect was also evidenced and is exemplified in the following commentary:

If you come from a space of respect and respecting them [MPRA learners] and seeing them for the potential of what they could be, then you get what you expect. They give it back to you, if you respect them ... we don't have a hierarchy here. I'm just Cheree, I'm not the CEO ... they know if you [care], it is from the heart. (Feats' Chief Executive Officer [CEO])

In addition, this attitude also exemplifies a strengths-based standpoint, rather than a deficit position. The CEO clearly articulated that she viewed these learners for their inherent potential "of what they could become" in the future, not defined by their past or why and how they ended up at Feats. This forgiving disposition expressed by the leadership also relates to the same value that was discussed by the youth.

Waypoint 3: Human dynamics. In terms of Waypoint 3, cultural identity was identified by the youth as being positively affirmed in the MPRA environment. Toru stated, "we don't get singled out [here] because we're Māori, we don't get singled out because we're Pasifika. Here we're all the same, it feels like we're just a family to be honest."

"Family" was a theme also consistent with collective will and the well-being of the group (Waypoints 3 and 4). The Fijian youth elaborates: "before at [Mainstream] School we had different groups, like the Islanders and Māori and Palagi [Pākehā]." It appeared that there they were segregated, rather than being a cohesive collection of combined cultures. Another youth originally from Kiribati concurred: "we just used to have beef. They [non-Pasifika] used to mock our language" in mainstream school settings. Seemingly, the educational backgrounds that these youth had come from, un/ intentionally, did not positively affirm their cultural identity. However, the MPRA environment appeared to align for them in terms of coming together as one collective "family" unit.

The level of self-knowledge for the MPRA focus group participants was enlightening. Toru who was self-reportedly "too angry to go to school" was vividly open about his "anger management" issues: "I was the angriest person . . . couldn't take a joke . . . because I couldn't handle the banter . . . I didn't have a sense of humour . . . just took it too serious" (Toru). A fellow student and close friend also reflected upon the role that he played in their relationship:

He always used to get angry every time I mocked him ... I'd tell him, don't take me serious . . . . I used to be a real shy person, didn't really like communicating with people. But now after this course I learnt I can talk to people and how to talk to them. (Wha)

Waypoint 4: Deepening practices. This Waypoint 4 is relational about connectivity and interpersonal relationships. At the MPRA, the youth said they learned much from "Story-Man" on their hourlong return journeys, twice a week, to and from the TRFUs 
headquarters in New Plymouth. On these 30-min each-way trips, "Story-Man," as the youth affectionately referred to him, was some kind of "All-Samoan' action hero who shared . . . life-changing stories. That's what it was - inspirational" (Toru). They genuinely "connected" with facilitators and the feeling was mutual.

Similarly, the TRFU and Feats' MPRA facilitators also demonstrated the importance of interpersonal relationship consistent with this waypoint when discussing their "jobs":

I still love going to work ... . It is not a place, it's a fantastic energy. Feats attracts the most amazing people. It is not financial for our facilitators . . . it is the same money as 26 years ago. It is about the reward of working with those people . . . and our partnership with TRFU is what makes it [MPRA] really special. (Feats' CEO)

I really love it .... Growing up and raised in Samoa, I always had that village community in my heart. I always loved people. I knew right from the start that rugby is just an extension of our lives. You know we coach skills and things like that, but in my heart, I just want to coach the people ... . I love it and it's not so much for the [MPRA] learners, but I'm learning myself too having been away from Samoa for a long time. I love connecting back into my fanau, into our PI community. (TRFU's MPRA manager)

Waypoint 5: Exploring and discovering new destinations. Employment and education opportunities were two major discussion points for the MPRA rangatahi (youth) in terms of exploring their future destinations and becoming leaders. Majority (eight out of 12) of MPRAs 2017 intake were so-called education "dropouts," many without formal qualifications and "at risk" of unemployment. However, in terms of social change at this education "plus-sport" site, post-MPRA, many rangatahi exited into employment. One of them in particular, who was geographically isolated and currently seeking employment, mentioned: "When I see my mates like ones who were on this [MPRA] course, they all have jobs now" (Wha). Another who was now in full-time employment post-MPRA and was apparently "not very talkative" or confident beforehand literally discovered his job through his online research and follow-up phone calls:

Ifound their [current employer] phone number on the internet, called them up, asked them if they were looking for workers and they said "yeah." Then they gave me a month's trial, I'm there full-time now. (Tahi)

This is not to be understated for someone who self-reportedly initially had no confidence. The other "job seeker" among the group proudly disclosed that he had positive news to share regarding his employment pathway:

I got accepted into work for the Fitness and Personal Training Course. I got a message the other day from the work tutors saying that I've been accepted. I start next month. Something cool that I can do . . . because I've got a lot of unfit people in my family ... not just me. (Toru)

Although these examples of positive outcomes were specific to the four in this focus group, they all agreed that these experiences were not atypical for the majority who graduated from the 2017 MPRA intake. The only exception, who was not employed or "job seeking," was "Rua" because he wanted to be a builder if he could not pursue his ultimate dream of being a professional rugby player.
Thus, he returned to his past school so that one day he would be able to "build my own house and my own furniture ... that's why I'm back doing Gateway."

This youth's pathway, post-MPRA, led him back into education once again. After admittedly not thriving in the mainstream, this young man returned to his former high school to pursue the NCEA Level 3 certification required for him to undertake a building apprenticeship. Primarily because "Feats" does not offer NCEA Level 3, but also because he felt like he had the capability to achieve success and flourish with his new skill sets, especially the confidence that the MPRA instilled in him to be brave and ask questions:

I came here [Feats] because some of my subjects were hard and I was struggling .... I've learned so much here [at Feats] that I've taken there [back into Mainstream]. Because at School I was always scared to ask questions, but here I could ask anything ... [Feats' facilitator] told me 'don't be scared, this is your home. These are your brothers and sisters'. (Rua)

For the record, in 2017, Feats enrolled 12 youth into the MPRA, 10 male and 2 female learners. Only four of these youth entered with NCEA Level 1, the other eight had no formal qualifications. By the end of the year, four of these eight who had no qualifications had achieved NCEA Levels 1 and 2, whereas another had completed Level 1, something that was seemingly impossible for them within mainstream education. For the four youth who entered with NCEA Level 1 already, three of them completed Level 2. The only one who did not complete NCEA Level 2 exited into full-time employment. These are all amazing feats for these youth potentially destined for other outcomes and labeled "at risk" by the mainstream system.

\section{E Tū Toa, hei tū he Rangatira-“Sport-Plus” Māori Development}

The "plus-sport" approach, practiced by the MPRA facilitators, provides interesting comparisons in terms of this "sport-plus" case. Again, results are organized according to the five waypoints.

Waypoint 1: Orientation. Again, a pepehā (narrative) is a traditional Māori ritual that connects people through whakapapa (genealogy) with their tupuna (ancestors) and tūrangawaewae (place of belonging). In Te Ao Māori (the Māori world), it is a rite of passage that grants access into the Māori world. In terms of entering the ETTMRD “sport-plus" site, rangatahi were required to deliver their pepehā on Day 1 in front of 43 other players and staff. During this whakawhanaungatanga (familiarization) ritual, most rangatahi, having come through the regional camp pathways, were able to competently and confidently deliver their pepehā and "e tū toa" (stand strong) during what can be an emotional and intimidating ritual. Others, however, were clearly not confident standing in Te Ao Māori to share their narrative. Indeed, a minority openly admitted that they "didn't embrace' fully their Māori whakapapa (genealogy) growing up." During the focus group interview, one of the rangatahi, for example, mentioned as follows:

It [ETTMRD regional camp] was, I guess, different [to Super Franchise camp] ... it was easier to fit in [there] compared to the Màori camp ... . I was not exactly comfortable like to talk in public [pepehā] or anything . . but nah I saw the value in it . . . still a good thing to do, finding out you're close relatives with other boys. (Iwa) 
When quizzed further about his comfortableness or awkwardness walking in Te Ao Māori he mentioned, he was "comfortably uncomfortable," primarily because he was raised in a predominantly Pākehā family and environment. The majority view of these rangatahi was encapsulated by a player who went to the same Super Franchise camp as well as the 2018 ETTMRD regional and 2017 National camps:

I think all Māori families, where you come from you're always going to appreciate your whanau and appreciate where you come from . . . well and truly, like I have no doubt the boys appreciate where they're from! That's just taught to us as young fellas and we uphold it going into our young adult life ... not just whanau, but also your friends as well. (Tekau)

Waypoint 2: Implementing values. Implementing identifiably Māori values was a determining driver at the ETTMRD campthey were everywhere to be seen, heard, felt, and lived. From our arrival at the pōwhiri (formal welcome ceremony) on Day 1 and everyday through to the poroporoaki (formal farewell) on our final night together. Tikanga (principles, protocols, and practices considered "right" in that context for that collection of people for their purposes) were observed by all and overseen by the Kaumatua of the MAB as well as the U18 team's own cultural advisor who kept everybody culturally safe within Te Ao Māori. The walls of the whare (house) where everybody slept, for example, had values, taonga and past Māori rangatira (leaders) pictured around the walls. The rangatahi were immersed in positive, affirmative messages of connection with tapuae (MAB rugby legacy), tribal affiliations (pepehā), maunga (mountain), awa (river), whēnua (land-base/ tūrangawaewae), whakapapa (genealogy), whānau (familial), wairua (spiritual), rangatira (chiefs), and ihi-wehi-tapu (excellence) urging them "to draw on their inner potential" (see Figure 2).

These concepts were imbued within and throughout the authentic 4-day "noho marae" wānanga (live-in, residential learning environment).

Another player mentioned a specific example that the entire focus group collectively agreed with regarding the value of being punctual as opposed to arriving late as follows:

We didn't clean up early enough. I guess he [culture advisor] was just trying to prove the point about be there [scheduled team meeting] on-time, trying to teach us a lesson, to be

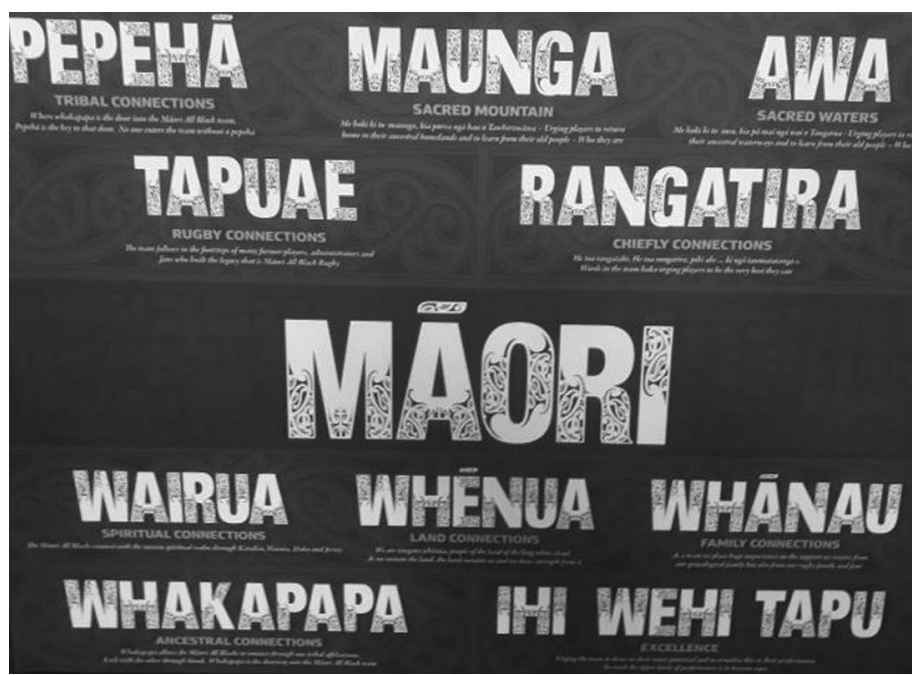

Figure 2 - Canvas picture taken from inside the wharenui. prepared and on-time ... he said it a few times over the camp 'on-time is late and early is on-time'. Time does count. You wouldn't turn up to a job interview late. I guess it is helpful for the future. (Whitu)

Implementing guiding values such as punctuality, along with respect and myriad others that were witnessed, to help orient these youth into leaders for tomorrow was a feature of this rugby "plus" Māori cultural development approach.

Waypoint 3: Human dynamics. Over the duration of the camp, the rangatahi had both on-field, rugby-specific, specialist coaching, but off-field they were also immersed in Te Ao Māori. Questions raised in the observational field notes, around cultural identity and well-being from the perspectives of players, were answered by a selection of these youth (six in total) at the follow-up focus group when asked to reflect upon their experiences and lived realities incamp as follows:

I think moving forward, you do look back at it and you have a bit more appreciation for it ... the atmosphere ... more of the environmental stuff. . . we came out with a better culture. I think that is what it is . . staying in a marae [traditional meeting house]. It just showed that when you're living with each other and breathing next to each other . . it comes out and shows on the field. The brotherhood that you can bond. (Tekau)

Counter to the upside of this positive cultural identity reinforcement, and related to this example, was a downside though. In terms of the short amount of time (4 days) spent together to prepare for a trial game, it proved taxing on individual and collective wellbeing in the group to commit not only to rugby trainings but also to tikanga trainings as well. In terms of physiological well-being, there were intense trainings without much recovery in between. Downtime and rest was an issue identified by all of the youth who reported that they would have appreciated more sleep. They did not mind rising early, but when they got to bed late (sometimes after midnight), waking up at 5:30 a.m. to complete daily chores was burning the candle at both ends. Their overall concurrence was best exemplified in this view as follows:

How do you expect us to perform when you're going to bed a 12 o'clock before the game, you know what I mean? I didn't like it [lack of sleep] at all to be honest. The Māori culture stuff was cool, but if you want us to succeed, it would have been nice to go to bed earlier so you can wake up early. One night I only got 5 hours sleep. (Ono)

Obviously, there were competing demands around messages and practices consistent with positive cultural identity affirmation and basic human functioning needs (i.e., sleep quality). However, the level of self-knowledge displayed by these youth was impressive. They understood what they were required to do in order to enable them to perform optimally, both as a rugby player but also as a rangatahi Māori as one mentioned "balance is the key." Being able to balance and align physical needs with the mental, emotional, spiritual, and social needs are fundamental for Indigenous (Māori) views of holistic well-being (Durie, 1999, 2001).

Waypoint 4: Deepening practices. The social well-being of individuals and groups also relates to Waypoint 4 and the interconnectivity between peoples' values with practices to support a holistic view that secures interpersonal relationships. On game-day morning, 
an impromptu encounter with the head coach and assistant coach occurred. They were viewing videos and photos of activities on the head coach's phone of the 2016 and 2017 ETTMRD campaigns. There was a link to the past programs and how this was impacting upon the well-being of present and future teams. The coaches talked openly about how far they had come since year one (2016) when they were "written-off" by their opposition teams and to some extent by NZRs lack of funding for them. They marveled at how the team's performances both on- and off-field had surprised everybody outside of their environment. This past-present-future theme also featured in the follow-up focus group with rangatahi:

Last year [2017] we kind of made a bit of a statement against the [NZ] Barbarians and then against Tonga. So I think NZ Rugby have brought into how Māori Rugby is and where we want to be ... it was good to see this year that the boys got better facilities, better gear . . . the coaching [including MAB Head Coach, NZR's kaumatua, past All Blacks' and MAB players] looked pretty sharp ... all I want to see is Māori rugby just keep developing and getting higher in the honours. (Tekau)

Following on from this theme about past, present, and future directions, Tekau, who represented the 2017 Māori U18s team, eluded to where they drew inspiration from as follows:

We heard stories ... of fighting for Māori rugby for so long. Trying to get camps started here for many years. After we heard that we knew we were there then .. . what can we do for the future? . . . we all bought into it pretty quickly just by hearing stories... definitely the camps last year [Regional/ National] done so much for me . . . it was those [ETTMRD] camps that got everything started. (Tekau)

Waypoint 5: Exploring and discovering new destination. This final waypoint speaks to the world of possibilities for today's rangatahi who will become tomorrow's leaders (rangatira) on and off the rugby field (Waypoint 5). When I asked them "where to next from here," they all had a pathway mapped out for 2019. Some had (semi)professional rugby aspirations, especially the two who made their franchise and regional ETTMRD camps:

I noticed after the [Super franchise] camp it has all come a lot clearer. I have got heaps of goals now. Long-term maybe the Hurricanes, short-term I'm looking at the [Heartland] team, it gets named this weekend. (Iwa)

Long-term a [fully professional] Super Rugby contract . . . and see what happens after that ... I just got called into the [semi-Pro team] due to a few injuries. (Tekau)

but professional rugby aspirations were not the final destination for all:

For me still at School. Rugby I just want to go wherever it takes me and just take my opportunity... if it comes. But I want to do an apprenticeship in Building. (Rima)

I don't actually know . . . last year in year eleven I just didn't know what I was doing . . . like at [old School] I played with him [Iwa] and [another invited youth not in attendance] for quite a while now. I have always been in their shadow, but I've looked up to them, try to get to where they are [Super Franchise U18s-level]. (Ono)

Next year I just want to stay in touch with my rugby if it's Māori [ETTMRD] or if it's [Super Franchise] . . . the learnings
I had at the camp the tikanga side of things like . . just the normal tapu [sacred] stuff, I want to actually . . . try and do what I did in camp back into my own living . . . normal rules you should try to uphold ... after I finish school I'm going to be an electrician. (Whitu)

I'm looking at studying marketing and management at Victoria University in Wellington and playing rugby for [Club]. (Waru)

From a wayfinding leadership perspective, the majority of these youth appeared to "know their island," their destinations were clear in terms of the direction they were heading. For some, their mapped-out pathways were rugby related, their aspiration was to become semi/professional athletes. For others, it would be staying in education either at secondary school or going on to university study, while the trade (builder, electrician) industries awaited others. Only one was not entirely sure which direction he was heading in, but he knew who his role models were and that he wanted to emulate their journeys in finding his own way.

\section{Discussion}

The case study results speak from the "ground up" in terms of offering homegrown voices. What follows is an integrated, topdown, theoretical discussion of the universal principles which ought to underpin sport for social change research by, with, and for Indigenous peoples: perspective, privilege, politics, protection, and people, as mentioned previously. In terms of structural and systemic politics, 20 years ago, prominent Māori scholar and rangatira (leader), Sir Mason Durie (1999) argued that there are increasingly:

reduced opportunities for cultural expression and endorsement within [Western] society's institutions. Too many [Māori] are unable to have meaningful contact with their own language, customs ... . too few institutions in modern NZ are geared towards the expression of Māori values, let alone language. (pp. 2-3)

Philosophically, this statement speaks to perspective. Sport, rugby in particular, has been one such institution in NZ society that has historically been politically geared toward cultural hegemony and assimilation (Cockburn \& Atkinson, 2017; Hapeta, 2017; Hapeta, Mulholland, \& Kuroda, 2015; Hokowhitu, 2005; Hokowhitu \& Scherer, 2008; Watson, Palmer, \& Ryan, 2017). The dominant group perspective is privileged in NZs institutions, in this case sport, with the "problem" being Indigenous perspectives of sport. For instance, Hokowhitu suggests that rugby is a site of cultural resistance fraught with contradictions in the postcolonial and neocolonial world where Māori gain and lose mana [prestige and power]:

the notion of a nationalistic New Zealand Māori team runs counter to New Zealand's egalitarian ethos, yet the control of the New Zealand Māori under the auspices of the NZRFU has left little room for it to be a tool for tino rangatiratanga [selfdetermination]. (Hokowhitu, 2005, p. 89)

For sport to enable positive social change and self-determination for Māori and Pasifika youth, the paternalistic perspectives of dominant majorities facilitating sporting experiences are what needs to be changed. Partnering with the people (youth), working alongside them, horizontally (Hodge, Henry, \& Smith, 2014) as opposed to 
vertically, where shared underlying values (Waypoint 2), human dynamics (Waypoint 3), and connectivity (Waypoint 4) were evidenced within these two case studies with positive outcomes.

In Australia, literature suggested that a paternalistic attitude was also the case when rugby was introduced there. Horton (2009), for instance, argued rugby "was part of the cultural hegemony of British imperialism, and it became a central element of the cultural fabric of the dominant [white, middle class, male] social groups in colonial Australia" (p. 968), and that it had been that way since the first club, Sydney University Rugby Football club was formally established circa 1865. Obviously, rugby was used in the colonies to change the ways of natives. Paternalistic superiority, however, is part of the problem in terms of the theory-practice gap. Sports can be used to promote social change, but mind-sets must also change (Spaaij, 2013). It is not the "at-risk" youth who need to change, but the system and structures also require greater scrutiny.

Regardless of which way around the plus comes (plus-sport/ sport-plus), Indigenous perspectives of sport for social change are also reflected in their struggle for well-being and health promotion. Durie suggested that "Māori health does not take shape in the human body alone, but within the trials and opportunities which make up human journeys" (1999, p. 1). The key elements that determine health and well-being, which Durie identified, include social, political, educational, economic, cultural, and historical factors.

In terms of NZ society, a secure cultural identity is a key to navigating the myriad pathways toward prosperous futures no matter which pathway one takes be it in education, sport, employment, or life in general. One of the key components required in order to be able to orient yourself is knowing where you come from (past), who you are (present), and where you are going (future). Thus, sport for social change initiatives must consider who or what needs changing. The status quo problematizes "at-risk" peoples who must change their "ways." This ignores wider society's institutional and political structures. This positioning only serves to protect those in power by privileging their worldviews, principles, theories, and practices. Future research in this sport for social change context should look to promote and protect the perspectives of Indigenous peoples rather than continue to colonize them through practice, theory, and research that does not reflect their needs or resonate with their realities.

For many Indigenous collectives, whakapapa (genealogy) is what grounds us; it anchors us as people to the whēnua (land), our tūrangawaewae (place of belonging). In wayfinding, "mauri stones" (heavy boulders) acted as protective anchors. Dropped overboard in testing conditions, they ensured that waka were not swept away in the tides or blown off course by strong winds. Indeed, they resisted the elements enabling wayfinders to be resilient, recharge, adjust their sails, and relaunch again. Indigenous (Māori) perspectives of well-being and health promotion suggest that our "mauri ora" (cultural identity) must be secure-just like the mauri stones-and positively reaffirmed (Durie, 2001). The two cases presented here from NZR settings positively reinforced the cultural identity of these Māori and Pasifika youth.

These practices also appeared to position youth well for flourishing futures where they could thrive in education and employment that may or may not include rugby. Instead of immersing these youth in the colonial process of deculturation, as witnessed in the mainstream educational and rugby systems, these youth were acculturated and actively encouraged to (re) connect with their culture. By embracing who they are as people and where they were from, these youth were privileged access back into their indigenous worlds and were encouraged to take these principles and worldviews and apply them to their present circumstances (education, careers, and rugby) and into their futures.

These rugby-related case studies (plus-rugby and rugby-plus) provided the vehicle (or waka) for youth to find their way. The Indigenous principles offered in this article that align with wayfinding leadership's waypoints (used to analyze the case studies) can also shine light on a way to navigate the distance between practice and theory in SFD research. The results demonstrated how youth in these Indigenous SFD initiatives navigated their intersecting worlds by learning and applying Indigenous principles, practices, and processes that gave them (and the program facilitators) culturally protective layers that kept them safe, not only within their Indigenous worlds, but also by learning resilience to thrive in wider society as Indigenous people of the world.

\section{Conclusions}

The case studies examined in this article showed Māori and Pasifika youth transforming their personal leadership journeys by referring to the five waypoints. This article demonstrates how we as Indigenous researchers also navigated the theory-practice intersect. We welcome other scholars writing in this area to refute and/or refine these five principles in terms of their Indigenous worldviews and case study experiences. At the "ground-up" level, the contribution this article made has illuminated two cases where rugby initiatives from NZ settings have guided youth toward more positive pathways and future directions both in rugby, alongside rugby, and after rugby. Not only in terms of educational achievement and employment prospects, but also as young Māori and Pasifika people who have a stronger sense of identity, which influences their sense of well-being, and creates opportunities for them to explore and discover how they transform their lives through tino rangatiratanga (self-determination) and whanaungatanga (collectivism). An aspiration that is encapsulated best in Figure 3.

This article has also argued that we need to know more about Indigenous approaches and practices to sport for social change. This is best done as a "native" researcher or pracademic who can empathize with principles underpinning Indigenous initiatives in research and practice such as perspective, privilege, politics, protection, and people.

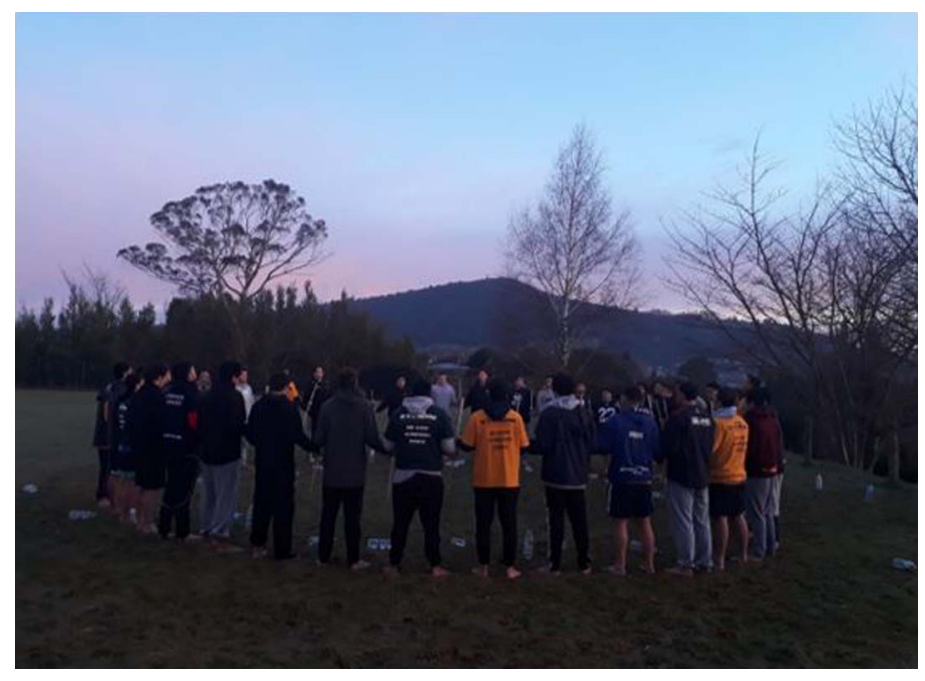

Figure 3 - Rangatahi e tū toa, hei tū he rangatira: Māori youth standing strong as leaders. 
Similar to the cases presented here, there are many others "out there" making a significant contribution to their communities at the grassroots level; practicing, living by, and connecting with Indigenous values, principles, and practices. One of the challenges facing non-Indigenous SFD researchers is how they can align their theories with these practices. Or, is it the expectation that these practitioners will connect and engage with SFD theorists?

A second overarching conclusion drawn from our analysis concerns theory-practice translations. Indigenous scholarship remains politically marginalized by many disciplines due to a lack of acceptance and understanding about other ways of first, knowing and second, knowledge production and sharing. As aptly argued, "it is imperative the SFD researchers develop a heightened awareness of what types of knowledge are dominating in SFD and what types of perspectives and understandings are being privileged, as well as better understand their limitation, bias, and partialities" (Spaaij et al., 2018, p. 34). Indigenous scholarship is not easily translatable to fit disciplinary molds for the purpose of mainstream convention, comprehension, and consumption. Much of the richness and meaning in Indigenous knowledge is "lost in translation." Many Indigenous scholars and practitioners face a multitude of challenges translating what they know and do so that it is palatable for a variety of audiences who perhaps are unaware of another way of seeing and being in the world, which is just as valuable and effective and in some cases more valuable and effective.

From an SFD perspective that embraces indigeneity and creates meaningful transformation, a more sustainable approach may be to adopt an "Indigenous plus" rather than "plus Indigenous" waka (vessel) to deepen practices (Waypoint 4) and create more connectivity. We need more Indigenous scholars, researchers, and pracademics in the SFD space to indigenize the theories that are used in this field of study.

These two higher level contributions reiterate the importance of including Indigenous voices in theory development within sport for social change and opens the door for a special issue on the subject. Synonymous with wayfinding, it is not always clear that what the destination will be, but what we can consider as a community of scholars are the waypoints and the principles we apply to get to our destinations. That at least is a respectful and genuine starting point to the journey.

\section{Notes}

${ }^{1}$ This said, we understand "theory" in itself is problematic and a contested concept because it is often predicated on particular sets of assumptions, propositions, or accepted facts which align with Western traditions of philosophy and understandings about what might exist and how this is then known (Smith, 2013).

${ }^{2}$ Keeping in mind that for many Indigenous peoples, the theory-practice relationship has been seriously disrupted and uncoupled as a result of colonization and ongoing marginalization. See Henry and Foley (2018) who in reference to research point out that "[i]n many instances the 'mainstream' non-Indigenous academic training that many Indigenous scholars received within the academy can taint, dominate, and limit their ability to research in a culturally safe and confident manner" (p. 214).

${ }^{3}$ We acknowledge that various SFD writers over the years has also made this point.

${ }^{4}$ There is still a lack of regard for ideas, values, beliefs, or epistemologies that are embedded deeply in a wider worldview. Rather, an instrumentalist approach to "how can we benefit" from incorporating facets of Indigenous knowledge is utilized. What constitutes valuable, valid, and reliable Indigenous knowledge; thus, it is still the dominant world order which decides which Indigenous knowledge is worthy of use and which cultural frameworks are useful. In deciding what is and is not "useful" Indigenous knowledges are placed in binary opposition to Western knowledges (Briggs \& Sharp, 2004, p. 667; Stewart-Withers, 2007, p. 13).

${ }^{5}$ Although this article focuses on the role of sport and rugby in particular as a development tool for Indigenous youth and/or from an Indigenous worldview, Pasifika, and Māori communities tend to be invested in rugby and experience similar levels of marginalization and discrimination in NZ society. One of the cases studied included both Māori and Pasifika youth, and so it was important to acknowledge the voices of Pasifika youth and analyze their experiences of SFD initiatives based on Indigenous practices and principles. Some non-Māori scholars even consider Māori as part of the Pasifika peoples collective along with Fijians, Tongans, and Samoans (Lakisa, Adair, \& Taylor, 2014).

\section{References}

Alvares, C. (1992). Science. In W. Sachs (Ed.), The development dictionary: A guide to knowledge as power (pp. 219-232). London, UK: Zed Books.

Arbon, V. (2008). Arlathirnda ngurkarnda ityirnda: Being-knowing doing: De-colonising Indigenous tertiary education. Teneriffe, Australia: Post Pressed.

Braun, V., \& Clarke, V. (2006). Using thematic analysis in psychology. Qualitative Research in Psychology, 3(2), 77-101. doi:10.1191/ 1478088706qp063oa

Braun, V., Clarke, V., \& Weate, P. (2016). Using thematic analysis in sport and exercise research. In Routledge handbook of qualitative research in sport and exercise (pp. 213-227). London, UK: Routledge.

Briggs, J., \& Sharp, J. (2004). Indigenous knowledges and development: A postcolonial caution. Third World Quarterly, 25(4), 661-676. doi:10. 1080/01436590410001678915

Coalter, F. (2007). A wider role for sport. Who's keeping the score. Oxon, UK: Routledge.

Coalter, F. (2010). The politics of sport-for-development: Limited focus programmes and broad gauge problems? International Review for the Sociology of Sport, 45(3), 295-314. doi:10.1177/1012690210366791

Coalter, F. (2013). Sport for development: What game are we playing? London, UK: Routledge.

Coalter, F. (2015). Sport-for-change: Some thoughts from a sceptic. Social Inclusion, 3(3), 19-23. doi:10.17645/si.v3i3.222

Cockburn, R., \& Atkinson, L. (2017). Respect and responsibility review. A commissioned report for New Zealand Rugby. Retrieved from http://nzrugby.co.nz/what-we-do/rugby-responsibility/respect-andresponsibility-review

Collison, H., Darnell, S.C., Giulianotti, R., \& Howe, P.D. (Eds.). (2018). Routledge handbook of sport for development and peace. London, UK: Routledge.

Cunningham, G.B. (2015). Diversity and inclusion in sport organisations (3rd ed.). Oxon, UK/New York, NY: Holcomb Hathaway Publishers.

Davidson-Hunt, I.J., \& O'Flaherty, R.M. (2007). Researchers, Indigenous peoples, and place-based learning communities. Society \& Natural Resources, 20(4), 291-305. doi:10.1080/08941920601161312

Durie, M. (1999, October). Te Pae Māhutonga: A model for Māori health promotion. Retrieved from http://www.hauora.co.nz/resources/ tepaemahutongatxtvers.pdf

Durie, M. (2001). Mauri ora: The dynamics of Māori health. Oxford, UK: Oxford University Press. 
Gardner, K., \& Lewis, D. (2000). Dominant paradigms overturned or 'business as usual'? Development discourse and the white paper on international development. Critique of Anthropology, 20(1), 15-29. doi:10.1177/0308275X0002000106

Hapeta, J. (2017). Is New Zealand rugby culturally blind or competent? Conference paper presented at the World in Union (New Zealand) International Rugby conference. Sport and Rugby Institute, Massey University, New Zealand.

Hapeta, J., Mulholland, M.\& Kuroda, Y. (2015). Tracking the stacking: The All Blacks from 1880-1980. Conference paper presented at World in Union (UK) Conference. University of Brighton, Brighton, UK.

Hapeta, J., Palmer, F., Kuroda, Y., \& Hermansson, G. (2019). A Kaupapa Māori, culturally progressive, narrative review of literature on sport, ethnicity and inclusion. Kōtuitui: New Zealand Journal of Social Sciences Online, 1-21.

Harvey, G. (2002). A step into the light: Developing a culturally appropriate research process to study Māori rangatahi perspectives of leisure in one setting. Waikato Journal of Education, 8, 71-82.

Henry, E., \& Foley, D. (2018). Chapter 10: Indigenous research: Ontologiesaxiologies, epistemologies and methodologies. In L.A. E. Booysen, R. Bendl, \& J.K. Pringle (Eds.), Handbook of research methods in diversity management, equality and inclusion at work (pp. 212-227). Northampton, MA: Edward Elgar Publishers.

Hodge, K., Henry, G., \& Smith, W. (2014). A case study of excellence in elite sport: Motivational climate in a world champion team. The Sport Psychologist, 28(1), 60-74. doi:10.1123/tsp.2013-0037

Hokowhitu, B. (2005). Rugby and tino rangatiratanga: Early Māori rugby and the formation of traditional Māori masculinity. Sporting Traditions, 21(2), 75-95.

Hokowhitu, B., \& Scherer, J. (2008). The Māori All Blacks and the decentering of the white subject: Hyperrace, sport, and the cultural logic of late capitalism. Sociology of Sport Journal, 25(2), 243-262. doi:10.1123/ssj.25.2.243

Horton, P. (2009). Rugby union football in Australian society: An unintended consequence of intended actions. Sport in Society, 12(7), 967-985. doi:10.1080/17430430903053216

Jeanes, R., \& Lindsey, I. (2014). Where's the “evidence?" Reflecting on monitoring and evaluation within Sport-for-Development. In K. Young \& C. Okada (Eds.), Sport, social development and peace (Research in the sociology of sport) (Vol. 8, pp. 197-217). Bingley, UK: Emerald Group Publishing Limited.

Kennedy, V., \& Wehipeihana, N. (2006). A stock take of national and international guidelines on health and disability research in relation to Indigenous people. Unpublished report. The National Ethics Advisory Committee Te Kahui Matatika o te Motu.

Lakisa, D., Adair, D., \& Taylor, T. (2014). Pasifika diaspora and the changing face of Australian Rugby League. The Contemporary Pacific, 26(2), 347-367. doi:10.1353/cp.2014.0029

Lee, J. (2009). Decolonising Māori narratives: Pūrākau as a method. MAI review, 2(3), 79-91.

Levermore, R. (2011). Evaluating sport-for-development. Progress in Development Studies, 11(4), 339-353. doi:10.1177/146499341001100405

Levermore, R., \& Beacom, A. (2009). Sport and international development. London, UK: Palgrave Macmillan.

Lyras, A., \& Welty Peachey, J. (2011). Integrating sport-for-development theory and praxis. Sport Management Review, 14(4), 311-326. doi:10 $.1016 /$ j.smr.2011.05.006

McGuire-Adams, T. (2017). Anishinaabeg women's stories of wellbeing: Physical activity, restoring wellbeing, and dismantling the settler colonial deficit analysis. Journal of Indigenous Wellbeing, 2(3), 90-104.
Onwuegbuzie, A.J., \& Frels, R. (2016). Seven steps to a comprehensive literature review: A multimodal and cultural approach. London, UK: Sage.

Paraschak, V. (2013). Hope and strength (s) through physical activity for Canada's Aboriginal peoples. In C.J. Hallinan, \& B. Judd (Eds.), Native games: Indigenous peoples and sports in the post-colonial world (pp. 229-246). Bingley, United Kingdom: Emerald Group Publishing Limited.

Pihama, L., Cram, F., \& Walker, S. (2002). Creating methodological space: A literature review of Kaupapa Māori research. Canadian Journal of Native Education, 26(1), 30-43.

Reddekop, J. (2014). 'Thinking across worlds: Indigenous thought, relational ontology, and the politics of nature; or, If only Nietzsche could meet a Yachaj' (PhD dissertation). University of Western Ontario, London, Canada.

Rigney, L.I. (1999). Internationalization of an Indigenous anticolonial cultural critique of research methodologies: A guide to Indigenist research methodology and its principles. Wicazo sa review, 14(2), 109-121. doi:10.2307/1409555

Rossi, T., \& Jeanes, R. (2016). Education, pedagogy and sport for development: Addressing seldom asked questions. Sport, Education and Society, 21(4), 483-494. doi:10.1080/13573322.2016.1160373

Rossi, T., \& Jeanes, R. (2018). Is sport for development already an anachronism in the age of austerity or can it be a space of hope? International Journal of Sport Policy and Politics, 10(1), 185-201. doi:10.1080/19406940.2017.1380682

Schulenkorf, N. (2012). Sustainable community development through sport and events: A conceptual framework for sport-for-development projects. Sport Management Review, 15(1), 1-12. doi:10.1016/j.smr .2011 .06 .001

Schulenkorf, N. (2017). Managing sport-for-development: Reflections and outlooks. Sport Management Review, 20(3), 243-251. doi:10.1016/j. smr.2016.11.003

Schulenkorf, N., \& Adair, D. (Eds.). (2014). Global sport-fordevelopment: Critical perspectives. London, UK: Palgrave Macmillan.

Schulenkorf, N., Sherry, E., \& Rowe, K. (2016), Sport for development: An integrated literature review. Journal of Sport Management, 30(1), 22-39. doi:10.1123/jsm.2014-0263

Smith, L.T. (2006). Researching in the margins issues for Māori researchers-A discussion paper. Alternative: An International Journal of Indigenous Peoples, 2(1), 4-27. doi:10.1177/117718010600200101

Smith, L.T (2013). Decolonising methodologies: Research and Indigenous peoples (3rd ed.). London, UK/New York, NY: Zed Books.

Smith, L.T., Maxwell, T.K., Puke, H., \& Temara, P. (2016). Indigenous knowledge, methodology and mayhem: What is the role of methodology in producing Indigenous insights? A discussion from mātauranga Māori. Knowledge Cultures, 4(3), 131-156.

Spaaij, R. (2013). Cultural diversity in community sport: An ethnographic inquiry of Somali Australians' experiences. Sport Management Review, 16(1), 29-40. doi:10.1016/j.smr.2012.06.003

Spaaij, R., Schulenkorf, N., Jeanes, R., \& Oxford, S. (2018). Participatory research in sport-for-development: Complexities, experiences and (missed) opportunities. Sport Management Review, 21(1), 25-37. doi:10.1016/j.smr.2017.05.003

Spiller, C., Barclay-Kerr, H., \& Panoho, J. (2015). Wayfinding leadership: Ground-breaking wisdom for developing leaders. Wellington, New Zealand: Huia Publishers.

Stake, R.E. (1995). The art of case study research. Thousand Oaks, CA: Sage Publications.

Statistics New Zealand. (2013). 2013 Census. Retrieved from http://www. stats.govt.nz/Census/2013-census.aspx 
Statistics New Zealand. (2015). New Zealand in Profile 2015: An overview of New Zealand's people, economy, and environment. Retrieved from http://archive.stats.govt.nz/browse_for_stats/snapshots-of-nz/nz-inprofile-2015.aspx

Stewart-Withers, R.R. (2007). Contesting development: The experience of female-headed households in Samoa [Unpublished PhD Thesis]. Massey University, New Zealand.

Vercoe, K. (2017). Māori participation in community sport review. Commissioned for Sport New Zealand by KTV Consulting Ltd.
Walker, R. (1990). Ka whawhai tonu matou. Auckland, New Zealand: Penguin Books.

Ware, F., \& Walsh-Tapiata, W. (2010). Youth development: Māori styles. Youth Studies Australia, 29(4), 18-29.

Watson, G.D., Palmer, F.R., \& Ryan, G.J. (2017). Aotearoa/New Zealand. In J. Nauright\& D. Wiggins (Eds.), Routledge handbook of sport, race and ethnicity (pp. 131-145). Oxon, UK: Routledge.

Young, K., \& Okada, C. (Eds.). (2014). Sport, social development and peace. Bingley, UK: Emerald Group Publishing Limited. 